\title{
Efeitos da situação pandémica COVID19 nos processos de aprendizagem e de investigação social: Resultados preliminares de um estudo exploratório qualitativo com estudantes em formação pós-graduada numa Instituição de Ensino Superior portuguesa
}

\author{
Sandra Saúde ${ }^{1}$ e Ana Isabel Rodrigues ${ }^{2}$
}

${ }^{1}$ Instituto Politécnico de Beja e CICS.NOVA - Centro Interdisciplinar de Ciências Sociais, Portugal | ssaude@ipbeja.pt | http://orcid.org/0000-0003-0935-1133

2Instituto Politécnico de Beja, Portugal | ana.rodrigues@ipbeja.pt | http://orcid.org/00000001-9140-9722

Resumo: Os confinamentos obrigatórios e as regras de distanciamento físico e socia impostos, um pouco por todo o Mundo desde inícios de 2020, devido à situação pandémica resultante do COVID19, alteraram profundamente as dinâmicas societais e de relação interpessoal. Entre o conjunto de atividades humanas afetadas destaca-se a da aprendizagem que foi forçada a transitar de um modo predominantemente presencial para online. Adicionalmente, e especialmente para os que desenvolvem investigação social, a esta mudança juntou-se o desafio de adaptação dos processos de pesquisa que, na área social, são estruturalmente baseados na riqueza da interação, preferencialmente, direta e presencial com o objeto de estudo. A fim de compreender a forma como tão significativas mudanças influenciaram a dinâmica de aprendizagem e de investigação, foi desenvolvido um estudo, de perfil exploratório e qualitativo, junto de estudantes em formação pós-graduada numa Instituição de Ensino Superior portuguesa. Para o efeito recolheram-se, via online e em dois momentos temporais distintos, as narrativas descritivas da sua opinião sobre os efeitos da situação vivenciada. A análise de conteúdo categorial temática efetuada, com o complemento exploratório do software T-LAB, permitiu concluir que para os estudantes, em análise, a situação influenciou negativamente a aprendizagem e o desenvolvimento dos processos de investigação. A quebra da vivência social plena forçou percursos de aprendizagem e de investigação muito individualizados e muito mais exigentes em termos de organização, motivação e resiliência pessoal. Acrescem as dificuldades sentidas ao nível da compatibilização do trabalho académico com a vida familiar, e, sobretudo, dos efeitos colaterais do medo e/ou da tristeza resultantes da manutenção da situação pandémica durante tanto tempo.

Palavras-chave: COVID19; Efeitos na Aprendizagem; Efeitos na Investigação Social; Ensino Superior; Formação Pós-graduada.

Effects of the Pandemic Situation COVID19 on Learning and Social Research Processes: Preliminary Results of a Qualitative Exploratory Study with Postgraduate Students at a Portuguese Higher Education Institution

Abstract: The lockdowns combined with the rules of physical and social distance imposed, all over the world in 2020 and 2021, due to the pandemic situation resulting from COVID19, profoundly changed the societal and interpersonal relationship dynamics. Among the set of human activities affected stands out the learning process, which was forced to move from a predominantly face-to-face to online format. Additionally, and especially for those who develop social research, this change has added the challenge of adapting the research processes, which, in the social area, are structurally based on the richness of interaction with the object of study, preferably direct and in-person. To understand how such significant changes influenced the learning and research dynamics, a study was developed, with an exploratory and qualitative profile, with students in postgraduate training at a Portuguese Higher Education Institution. For this purpose, were collected, online in two different time periods, descriptive narratives of their opinion on the effects of the experienced situation. The thematic categorical content analysis carried out, with the exploratory complement of the T-LAB software, allowed to conclude that for the students, in analysis, the situation had a negative influence on the processes of learning and research development. The breach of full social experience forced very individualized and much more demanding learning and research paths in terms of organization, motivation, and personal resilience. Added to this greater demand are the difficulties felt in matching the academic work with the family life, and, above all, with the collateral effects of fear and/or sadness resulting from the maintenance of the pandemic situation for so long.

Keywords: COVID-19; Effects on Learning; Effects on social research; Higher Education; Postgraduate training. 


\section{Introdução}

A pandemia resultante do vírus SARS-CoV-2 alterou profundamente as dinâmicas sociais. Desde inícios do último ano (2020), fomos forçados a ficar em casa, em confinamento obrigatório, por períodos longos ${ }^{1}$ e a mudar drasticamente os nossos hábitos de convívio social. A nível educativo, as aulas presenciais foram substituídas pelo regime a distância, com recurso a plataformas tecnológicas variadas, com componentes de comunicação síncrona e assíncrona. De um modelo em que a dinâmica pedagógica se alicerçava na relação presencial interpessoal passámos para um modelo de contacto a distância, em que cada um, docente e estudante, a partir da sua casa procura prosseguir o percurso de ensino-aprendizagem.

Ao nível da investigação científica, particularmente a de natureza social, também, novos desafios foram colocados decorrentes do distanciamento físico e social obrigatórios que passaram a impedir recolhas de dados presenciais e forçaram ajustamentos significativos nos desenhos iniciais de investigação.

O Ensino a Distância (EaD) e a Investigação a Distância (laD), ou eminentemente online, são processos que, sendo expressão da situação atual, impõem desafios novos a quem os tem de desenvolver, ainda para mais, porque foram assumidos, abruptamente, num contexto de "emergência" e de única alternativa. Mas, sendo a solução possível, até que ponto está a ser eficaz? Quais os principais aspetos positivos e negativos da experiência desenvolvida? De que forma a situação pandémica, e a experiência de laD, está a afetar os percursos de investigação social em curso? Estas são algumas das questões que orientaram o estudo efetuado com um conjunto de estudantes em formação pós-graduada numa Instituição de Ensino Superior (IES) portuguesa. Procurámos, através de um estudo exploratório de perfil qualitativo, explorar e compreender, na ótica dos estudantes, os efeitos induzidos pelas experiências vivenciadas, em contexto pandémico, de $\mathrm{EaD}$ e de investigação social, na aprendizagem e no desenvolvimento dos seus projetos de pesquisa.

\section{EaD e laD: Características e Desafios no Contexto Atual}

Apesar da consistente evolução e diversificação do EaD registada nos últimos anos, a massificação do seu uso só agora se verificou por necessidade imperiosa e para permitir a continuação das atividades de ensino-aprendizagem, em contexto pandémico.

O EaD tem pressupostos pedagógicos específicos que implicam uma consistente e planeada articulação entre objetivos de aprendizagem, opções didáticas e recursos tecnológicos. O regime de EaD obriga a um coerente planeamento e domínio de estratégias pedagógicas e de promoção de aprendizagem em ambiente tecnológico de forma a estimular a atenção, a motivação e a participação dos estudantes (Moore, Dickson-Deane, \& Galyen, 2011).

O que se está a passar (e passou), no entanto, na grande maioria dos casos é a simples aplicação online, via plataformas de comunicação, do inicialmente pensado para o modelo presencial (Cabero Almenara \& Valencia-Ortiz, 2020; Mineiro \& Lagarto, 2020).

As práticas constatadas demonstram, também, a questionabilidade da assunção de que todos têm competências suficientes para fazer uso da tecnologia; tal é particularmente verdade ao nível da sua incorporação e exploração educativa.

1 Em Portugal, o primeiro confinamento geral foi entre março e abril de 2020 e o segundo, entre janeiro e abril de 2021, ao que acrescem os confinamentos parciais, registados ao longo de todo o último ano e que ainda se mantêm, determinados para municípios específicos, em função da sua maior taxa de contágio. 
Em termos pedagógicos, o que se conseguiu garantir não foi além do denominado ensino não presencial de emergência (Hodges, Moore, Lockee, Trust, \& Bond, 2020; Mineiro \& Lagarto, 2020) que teve influência nas dinâmicas de ensino-aprendizagem, e expôs, ainda mais, a influência que os distintos (e desigualitários) contextos individuais e sociais partilhados pelos estudantes têm na sua capacidade, motivação e disponibilidade para aprender (Katz, Jordan \& Ognyanova, 2021).

No caso da investigação social, o recurso a ferramentas para a operacionalização da recolha e/ou análise de dados a distância é algo que ganhou aplicabilidade e crescente utilização nas últimas décadas. O que é verdadeiramente novo e mais exigente, na atualidade, é o fato do uso dessas ferramentas ter passado de complementar a única opção disponível, dada a impossibilidade de realizar presencialmente as observações. Emergem novos desafios sobre os formatos de observação e as formas de a realizar, bem como, sobre questões éticas e/ou de respeito pela proteção dos dados pessoais (Barroga \& Matanguihan, 2020). Há novos recursos que diversificam as oportunidades e as técnicas de recolha de dados, mas, que, também, exigem maior capacidade de ponderação entre potencialidades e os seus respetivos fins.

Face às ferramentas tecnológicas atualmente disponíveis, nem a exequibilidade, nem a cientificidade das pesquisas estão postas em causa (exceção, talvez feita, aos estudos etnográficos com fortes componentes de observação participante e direta incorporadas e/ou pesquisas que envolvam a recolha de dados em contextos onde o acesso à internet é difícil ou mesmo impossível), na medida em que há alternativas para a recolha de dados com suporte online, no entanto, há que saber adaptar os desenhos metodológicos face ao novo contexto (Kara \& Khoo, 2020).

Quer a nível pedagógico, quer ao nível da investigação social, este "novo normal" induziu, também, desafios positivos ao estimular a criatividade no uso das ferramentas de comunicação e de observação direta e indireta, síncrona e assíncrona atualmente disponíveis. Temos ao dispor uma multiplicidade de recursos que permitem estimular a aprendizagem interativa, implementar comunidades de prática e de reflexão (Basak, Wotto \& Bélanger, 2016), dinamizar mais facilmente entrevistas individuais e/ou de grupo, tornar mais atrativa a resposta a questionários, agilizar a análise e a revisão partilhada a distância de resultados preliminares de investigação (Nind, Coverdale \& Meckin, 2021) e, até, garantir a observação de detalhes físicos de uma rua, estando em casa, a quilómetros de distância².

Em contexto societal tão distinto e único, como é que as novas (e forçadas) dinâmicas de $\mathrm{EaD}$ e de laD estão a ser experienciadas? É essa a resposta que procurámos obter junto de um grupo de estudantes que viveu durante o último ano e vive, ainda, atualmente essas experiências pela primeira vez.

\section{Metodologia}

\subsection{Objetivo do Estudo e Questões Orientadoras}

O estudo realizado teve como objetivo central: compreender os efeitos induzidos pelas experiências vivenciadas, em contexto pandémico, de EaD e de investigação social, na aprendizagem e de desenvolvimento projetos de pesquisa, tendo por base a opinião de uma amostra intencionalmente selecionada de estudantes em formação pós-graduada numa IES portuguesa.

Assumiram-se como questões orientadoras do estudo, as seguintes:

Q01: Quais os principais aspetos positivos e negativos que os estudantes associam à experiência EaD vivenciada?

\footnotetext{
${ }^{2}$ Através do Google Earth e/ou do Google Street View.
} 
QO2: Qual a avaliação feita pelos estudantes sobre o efeito da experiência EaD na motivação para estudar?

QO3: Qual a avaliação feita pelos estudantes sobre o efeito da experiência EaD na aprendizagem?

Q04: Qual a avaliação feita pelos estudantes sobre o efeito da situação pandémica no percurso de investigação?

Q05: Quais os principais aspetos positivos e negativos, impostos pela situação pandémica, nos percursos de investigação, na opinião dos estudantes?

Foi desenvolvido um desenho metodológico de natureza exploratória de perfil qualitativo baseado na recolha, análise e interpretação das categorias estruturantes da opinião tida pelos estudantes sobre os principais efeitos sentidos nos seus percursos de aprendizagem e de investigação social devido à alteração forçada nos modelos de ensino e de pesquisa. Estes estudantes passaram pela experiência dupla, ao longo do ano de 2020, de alteração do modelo de aulas presenciais para o modelo a distância, entre março e junho, e depois a partir de setembro, pela obrigatoriedade de adaptar os seus projetos de investigação, no âmbito das suas dissertações, para um formato de laD.

\subsection{Procedimentos e Instrumentos de Recolha de Dados}

As opiniões dos estudantes foram recolhidas em dois momentos temporais distintos. A suscitação das narrativas relativas à forma como avaliam os efeitos do $\mathrm{EaD}$ foi feita em junho de 2020, aquando do final do segundo semestre de aulas ${ }^{3}$. A opinião sobre a experiência de laD foi partilhada em fevereiro de 2021, cinco meses decorridos desde o início dos trabalhos de investigação social.

Para a recolha da opinião sobre a experiência de $\mathrm{EaD}$ foi aplicado um questionário online constituído por cinco questões. As perguntas foram alvo de um processo de validação prévio por uma especialista em métodos e técnicas de investigação social ao que acresceu o de verificação da fiabilidade e de consistência interna da escala de Likert aplicada em duas questões.

As duas primeiras perguntas, relativas aos aspetos positivos e negativos que os estudantes atribuem à experiência de $\mathrm{EaD}$, e a quinta questão, de justificação da avaliação global feita sobre o efeito do $\mathrm{EaD}$ na aprendizagem, são de natureza aberta. A terceira e a quarta questões, de avaliação do efeito do $\mathrm{EaD}$ na motivação para estudar e na aprendizagem, foram estruturadas de acordo com a escala de opinião de Likert de 5 pontos, sendo que 1 é representativo de efeito muito negativo a 5 de efeito muito positivo. A fiabilidade das duas escalas foi comprovada via alfa de Cronbach $(0,896 ; 0,946$ respetivamente).

A opinião sobre o efeito da alteração forçada do percurso de investigação devido à pandemia, foi recolhida via online junto de um subgrupo dos estudantes inquiridos na primeira fase.

${ }^{3} \mathrm{O}$ início das aulas em formato a distância ocorreu em março de 2020 e manteve-se ao longo de todo o semestre, correspondente ao segundo semestre do ano letivo de 2019/2020. 
Estes estudantes foram selecionados por terem iniciado os seus processos de pesquisa em setembro de 2020 e por estarem mais próximos das autoras desta investigação facilitando, assim, a partilha mais espontânea de pontos de vista e sentimentos. A opinião foi dada em resposta a três questões de natureza aberta, a saber:

- Como a pandemia afetou o seu percurso de investigação?

- Quais os principais aspetos positivos induzidos pela situação pandémica nos percursos de investigação?

- Quais os principais aspetos negativos induzidos pela situação pandémica nos percursos de investigação?

Nos dois momentos de recolha de dados foram cumpridas as regras éticas e de proteção de dados em vigor, tendo todos os inquiridos aceite participar mediante consentimento informado.

\subsection{Participantes do Estudo}

O primeiro instrumento de recolha de dados foi aplicado a um grupo de 24 estudantes a frequentar o $2^{\circ}$ semestre do $1^{\circ}$ ano de um curso de mestrado. A taxa de retorno foi de $100 \%$.

No segundo momento de recolha de dados participou um subconjunto do grupo inicial de estudantes, ao total oito, selecionados intencionalmente porque:

1) Tendo prosseguido para o $2^{\circ}$ ano do curso, foram os primeiros a iniciar os percursos de investigação (em setembro de 2020) possuindo, assim, o maior tempo de experiência de laD possível;

O estudo é exploratório e de recolha de primeiras evidências sobre a problemática. Os dados apurados são apenas válidos para o grupo de participantes em análise. Adicionalmente:

- Foi assegurado total anonimato aos participantes não sendo possível identificar o(a) respetivo(a) emissor(a) das opiniões partilhadas sobre a experiência de EaD;

- Na fase de recolha de dados sobre a experiência de laD, o foco esteve exclusivamente na forma como cada um(a) do(a)s estudantes está a vivenciar o seu percurso de investigação. A partilha feita, por não envolver aspetos de "avaliação objetiva ou subjetiva" da relação mantida com as investigadoras, não foi influenciada negativamente por esse fato. Considera-se, adicionalmente, que o prévio conhecimento tido facilitou a espontaneidade e a riqueza das narrativas partilhadas na medida em que foram recolhidas por investigadoras que são conhecedoras da fase processual em que se encontram na formação pós-graduada.

\subsection{Técnicas de Análise de Dados}

Através do primeiro instrumento de recolha de dados foram obtidos dados de natureza qualitativa e quantitativa. Nas três questões, de natureza aberta, foram recolhidas, em cada, 24 respostas ou unidades sintáticas que formam o corpus que foi alvo de análise de conteúdo. Face aos objetivos do estudo optou-se pelo desenvolvimento de uma análise categorial temática que permitiu identificar as categorias estruturantes da opinião tida pelos estudantes dos principais aspetos positivos, negativos e efeitos na aprendizagem que associam à experiência de EaD. Prévio à identificação das categorias de significado emergentes, foi feita, com recurso ao software T-LAB uma análise exploratória do corpus extraindo as primeiras ideias ou palavras-chave mais repetidas. Foi adicionalmente feita uma análise de coocorrências, através da verificação da "Associação de palavras". As categorias temáticas emergiram através da agregação e interpretação em subconjuntos das partes extraídas das unidades sintáticas com significante comum. 
O processo de tematização surgiu como forma de "arrumar" um conjunto de ideias similares e repetidas que ajudam a interpretar um dado fenómeno (Saldana, 2009). A categorização descritiva de palavras (unidades de análise) foi realizada com base na tematização dos dados.

Para a análise das respostas obtidas nas três questões abertas relativas à opinião tida sobre os efeitos da situação pandémica nos percursos de investigação social foram repetidos os procedimentos.

No que respeita aos dados de natureza quantitativa (obtidos nas duas questões em escala de opinião) constantes no instrumento de recolha da avaliação feita da experiência de $\mathrm{EaD}$, foi desenvolvida uma análise através de estatística descritiva.

\section{A Opinião dos Estudantes de uma IES Portuguesa sobre os Efeitos do EaD na Aprendizagem e da Alteração Forçada dos Processos de Investigação Social}

\subsection{A Opinião sobre os Efeitos do EaD, em Tempos de COVID19, na Aprendizagem e na Motivação para Estudar}

Tendo em conta a experiência vivenciada de $\mathrm{EaD}$, durante o segundo semestre letivo de $2019 / 2020$, foi solicitado aos inquiridos que identificassem os seus principais aspetos positivos e negativos.

Em relação aos aspetos positivos da experiência são associadas como principais palavras/lemas: a) tempo; b) conforto; c) casa; d) deslocação; e) gravação; f) família; j) repetição (Tabela 1).

Tabela 1. Palavras mais repetidas nas unidades sintáticas registadas para os principais aspetos positivos do EaD

\begin{tabular}{cc}
\hline ITEM & OCC \\
\hline TEMPO & 21 \\
CONFORTO & 18 \\
CASA & 18 \\
DESLOCAÇÃO & 15 \\
GRAVAÇÃO & 12 \\
FAMILIA & 11 \\
REPETIÇÃO & 10 \\
\hline
\end{tabular}

Legenda: Item=palavras/lemas; $O C C=$ número de repetições

Fonte: T-LAB Plus 2020, questionário aplicado em junho 2020

Associado à palavra-chave "Tempo" os inquiridos associam como "principais ideias" (Fig. 1):

- Não ter de fazer "deslocações", ganhando-se tempo para a "família", para o estudo da "matéria" e para ter mais foco na "aprendizagem". Para além disso é mais "confortável", beneficiando, em parte, o "conhecimento" adquirido. Também são associados à "característica" Tempo - a "autonomia" (que há que saber gerir melhor) e "internet" (já que a experiência de EaD assenta no uso essencial desse recurso). 
Vol. 9 | Investigação Qualitativa em Ciências Sociais: Avanços e Desafios

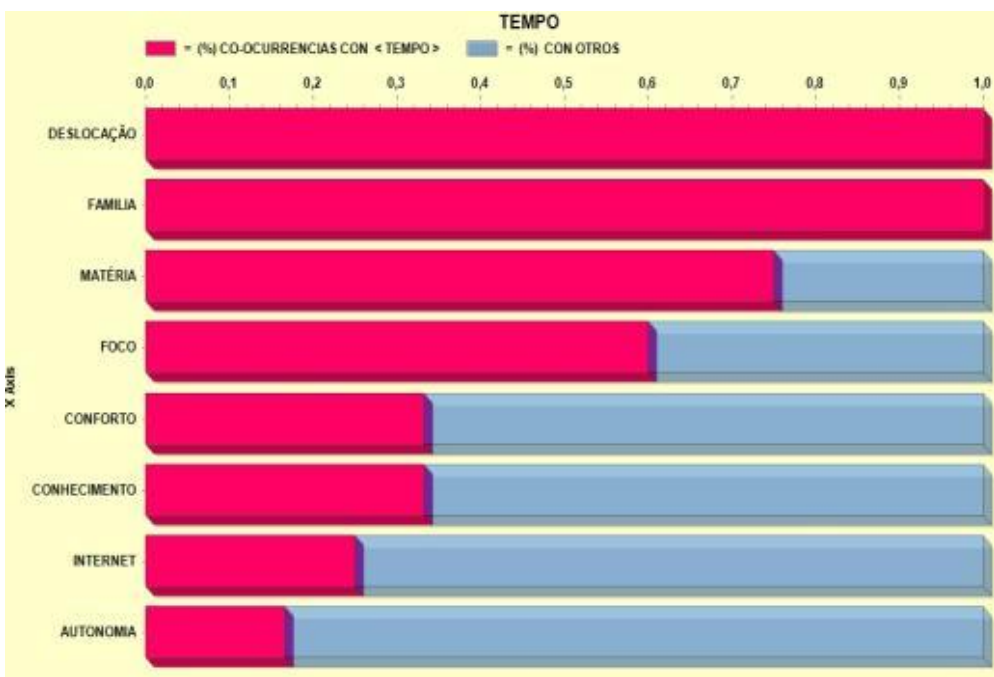

Fig. 1. Palavras mais associadas à palavra-chave: Tempo Legenda: $O$ índice de associação varia entre 0 e 1.

Fonte: T-LAB Plus 2020, questionário aplicado em junho 2020

Em relação aos aspetos negativos da experiência de EaD destacam:

- É baseado em maior/excessivo volume de trabalho para desenvolver:

E3: "Existe uma maior carga de trabalho no ensino à distância."

- É baseado em maior/excessivo volume de aulas teóricas/só expositivas:

E24: "No ensino à distância, as aulas são mais exaustivas, mais teóricas."

- Induz pior interação/relação com o professor:

E18: "Contacto com os professores é apenas feito via internet."

- Induz pior interação/relação com os colegas:

E2: "A dinâmica da relação entre alunos, colegas é muito prejudicada."

- Prejudica a dinâmica relacional da turma:

E20: "A inexistência de contacto entre professor e alunos."

- É mais cansativo do ponto de vista físico e emocional:

E14: "(...) o ensino à distância é mais cansativo, porque passamos horas em frente ao computador e não é saudável."

- Dificulta a comunicação na turma/participação nas aulas:

E6: "No ensino presencial a partilha e troca de ideias é mais intensa e intuitiva."

- É um método muito influenciado/dependente da qualidade da internet:

E5: "(...) existem alunos e até professores que não têm as mesmas possibilidades de acesso à computadores ou à Internet, o que é um problema."

No que respeita à opinião tida sobre o efeito do $\mathrm{EaD}$ na motivação para estudar (Fig. 2): $44,4 \%$ avalia como tendo tido um efeito "negativo a muito negativo". 
Vol. 9 | Investigação Qualitativa em Ciências Sociais: Avanços e Desafios

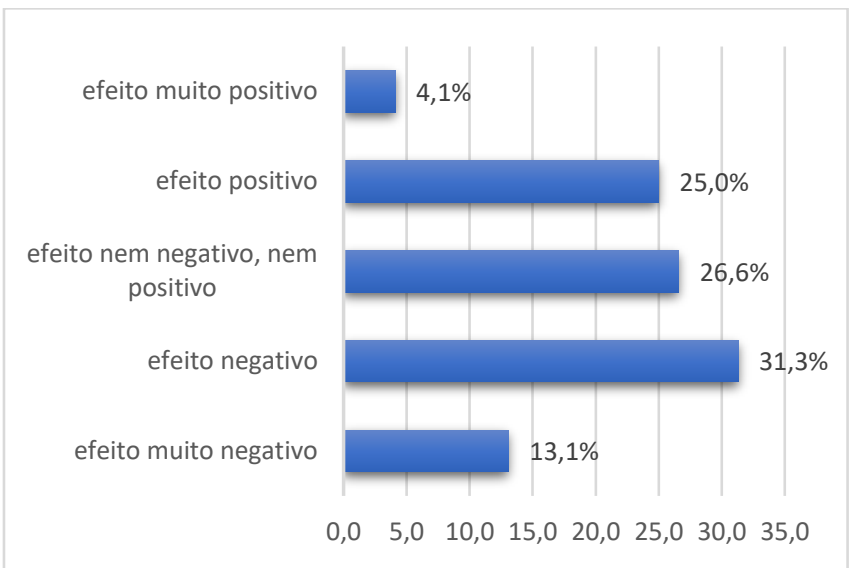

Fig. 2. Opinião sobre o efeito da EaD na motivação para estudar

Fonte: Excel 2008, questionário aplicado em junho 2020.

É ao nível do efeito na aprendizagem que a avaliação dos estudantes é mais negativa; para $59,3 \%$ a experiência de EaD teve um efeito negativo a muito negativo $(48,4 \%$ e 10,9\%, respetivamente) (Fig. 3).

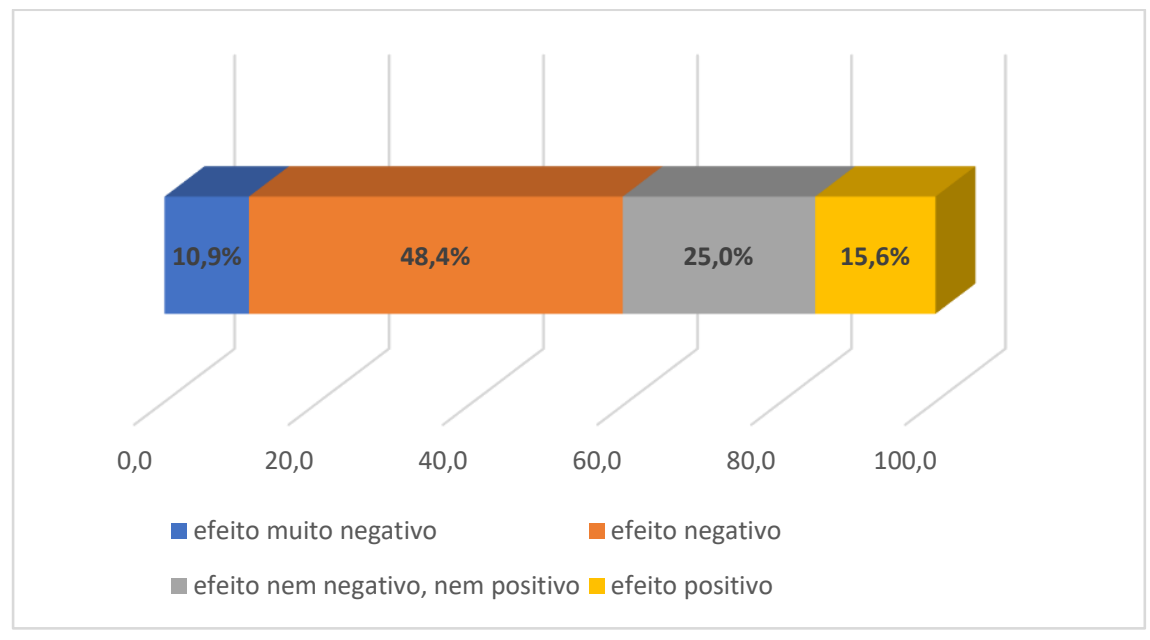

Fig. 3. Opinião sobre o efeito da $\mathrm{EaD}$ na aprendizagem

Fonte: Excel 2008, questionário aplicado em junho 2020.

Para justificar a opinião, e de acordo com a análise de conteúdo categorial temática efetuada, destacam-se como principais efeitos:

- Menor atenção/menor concentração;

- Maior desinteresse;

- Comunicação mais difícil com o professor;

- Contacto/interação mais difícil com os professores;

- Contacto/interação mais difícil com os colegas/turma;

- Maior dificuldade para tirar dúvidas;

- Menor motivação;

- Aumento exponencial do volume de trabalhos a desenvolver;

- Maior dificuldade na realização dos trabalhos de grupo;

- Compreensão mais difícil da matéria;

- Maior cansaço físico e emocional pelo formato expositivo/teórico das aulas. 


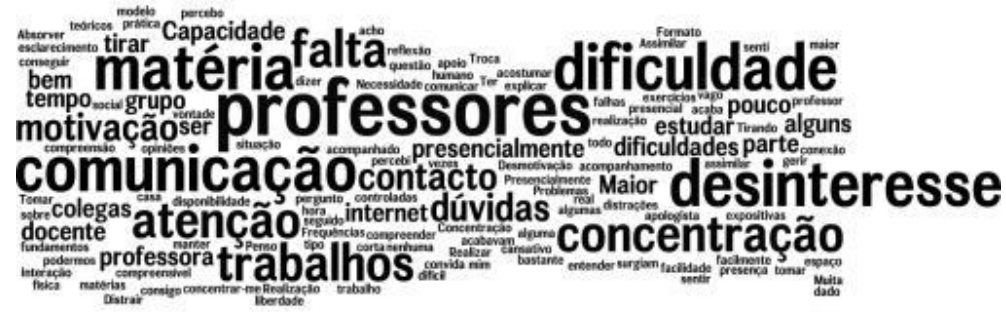

Fig. 4. Nuvem de palavras mais associadas às dificuldades de aprendizagem sentidas no formato EaD

Fonte: nuvem de palavras construída através de Worldclouds, questionário aplicado em junho 2020.

\subsection{A Opinião sobre os Efeitos da Pandemia COVID19 nos Processos de Investigação Social}

A situação pandémica implicou a introdução de modificações nos planos de pesquisa inicialmente equacionados pelos estudantes. Todos os estudantes estão a desenvolver formação pós-graduada na área das ciências sociais e o desenho de investigação, que passaria por recolha direta e presencial de dados, teve de ser adaptado. As entrevistas exploratórias passaram a ser desenvolvidas em formato online, as observações diretas e presenciais em contexto tiveram de ser reajustadas e a imediatidade, típica da recolha de dados com as pessoas nos seus próprios contextos, perdeu-se.

Adicionalmente, os contactos com colegas e com os orientadores passam-se a fazer à distância, nomeadamente por videoconferência. Novas dúvidas emergem relacionadas com a proteção de dados dos entrevistados online e/ou com o domínio das ferramentas tecnológicas de comunicação a distância. Passam-se muitas mais horas ao computador que têm de ser combinadas com a vida profissional, dado o teletrabalho, e a vida familiar. O cansaço da denominada "televida" começa a emergir; já são muitos meses e dias de confinamento, mais ou menos limitadores, em que se torna cada mais difícil manter o foco e encontrar alternativas para não perder, totalmente, a motivação. Esta é uma síntese da avaliação feita pelos estudantes sobre: como a pandemia afetou o seu percurso de investigação. As palavras-chave mais repetidas nas respostas dadas constam na nuvem de palavras apresentada na Figura 5.

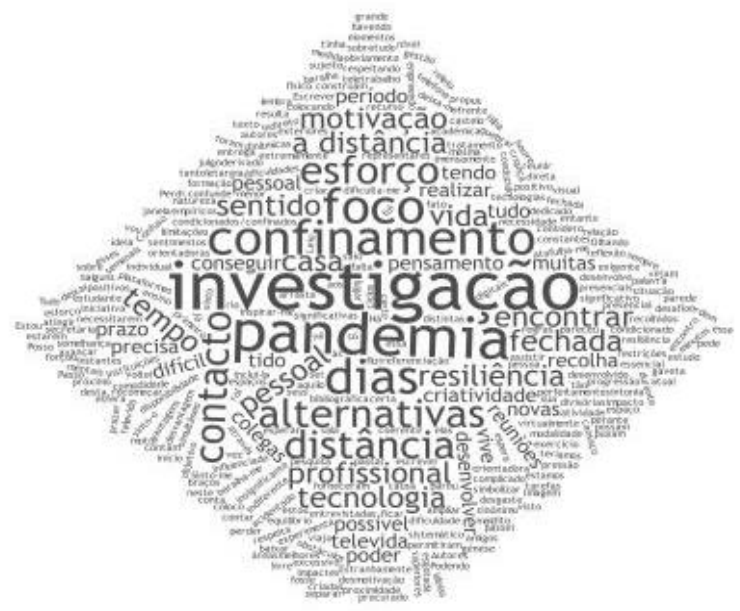

Fig. 5. Nuvem de palavras mais repetidas na avaliação do efeito da pandemia no percurso de investigação

Fonte: Identificação das palavras mais repetidas efetuada através do T-LAB2020 e nuvem de palavras construída através de Worldclouds, recolha de dados efetuada em fevereiro de 2021. 
A opinião de que a pandemia tem tido um efeito negativo no processo de investigação é assumido por seis dos oito estudantes envolvidos no estudo. Entre os efeitos mais negativos destacam-se:

- A impossibilidade de realizar o processo de investigação num ambiente natural e não condicionado pelo medo do contacto físico;

E1: "A pandemia afetou a investigação, em primeiro lugar pelo fato de estamos condicionados/confinados em relação a restrições de contacto entre pessoas e não ser possível um contacto mais próximo com as instituições e os seus representares."

- O receio de que o efeito da pandemia nas dinâmicas societais possa alterar, artificialmente, os resultados da investigação;

E6: "O que estou a estudar é um problema cuja opinião atual das pessoas em muito foi alterado pela pandemia. Antes da pandemia atrair pessoas para o território e como o fazer era a solução que todos procuravam. E agora? As pessoas têm receio dos que aparecem de novo. Será que vão continuar a pensar da mesma forma?"

- O facto de tudo ter de ser feito através do computador e/ou online, o que exige novas competências;

E4: "Tudo é feito online. Temos que dominar o ZOOM, o Teams, o Skype, os procedimentos de gravação, o google forms, a pesquisa na net e as plataformas de pesquisa, enfim... a investigação social passou a ser tudo em formato eletrónico o que exige mais competências e mais tempo de aprendizagem."

- O cansaço físico e emocional pela obrigatoriedade da "televida";

E8: "A "televida" baralha-me os espaços mentais, "atafulha-me" a mesma gaveta de um rol de tarefas, obviamente a necessitarem de divisórias, de tão distintas entre elas. E dificulta-me, sobretudo, o prazer da reflexão, da progressão de uma ideia que abraço."

- A acrescida dificuldade de compatibilização da vida familiar e profissional com o trabalho académico;

E3: "A situação atual, em muito tem influenciado e até condicionado a minha investigação, o facto de ter uma criança menor em casa a assistir às aulas na modalidade de ensino à distância acaba por ocupar muito do meu tempo. Também tenho sentido muita dificuldade em gestão do tempo e em encontrar o foco."

- O cansaço emocional resultante da gestão dos efeitos da situação pandémica;

E1: "E também por não conseguir ficar indiferente aos meus sentimentos, perante a pandemia."

- A falta de contacto mais próximo com os colegas de turma, porque todos estão envolvidos na gestão emocional da situação;

E3: "Sinto a falta das conversas de turma, mas as que tínhamos no primeiro semestre, tudo foi mudado com as aulas a distância. Faz-nos falta falarmos uns com os outros para tirar dúvidas. Mas, agora, mesmo que falemos já não é com a mesma coisa todos estão muito fartos disto." 
Entre os efeitos positivos, são destacados:

- Maior facilidade na realização das entrevistas pela não necessidade de deslocações;

E2: "Ganhei tempo em algumas entrevistas porque não implicou que me deslocasse."

- Maior investimento nas pesquisas online devido ao confinamento obrigatório;

E4: "Já que passamos mais tempo envolvidos com as tarefas, não saímos temos também mais tempo ao computador vamos aproveitando para fazer mais pesquisas. Até é bom."

- Alargamento do tempo de realização das dissertações.

E8: "Foi-nos dado um tempo adicional, pouco, mas até é uma pequena consequência positiva."

\section{Análise e Discussão dos Resultados}

Globalmente, os participantes fazem uma avaliação não positiva da experiência de $\mathrm{EaD}$ e de laD; identificam mais aspetos negativos do que positivos.

Ao detalhar a experiência de EaD tida assumem não terem gostado, particularmente, da falta de dinâmica relacional presencial com colegas e professores e do facto de a formação online induzir maior distração, menor foco e até menor motivação para a aprendizagem. Entre os aspetos perturbadores também são destacados, por um lado, o facto de ser uma modalidade de ensino-aprendizagem muito dependente da qualidade da internet e dos recursos informáticos e, por outro lado, ser mais cansativo por exigir muitas horas de trabalho em frente ao computador. A maioria dos estudantes assume que a experiência prejudicou a sua aprendizagem, com influência negativa na motivação para estudar.

Os resultados apurados divergem dos obtidos nas múltiplas investigações que comprovam as mais valias da educação a distância para o sucesso da aprendizagem e para o aumento do interesse e da motivação do estudante (Arkorful \& Abaidoo, 2015; Pearson, Singelmann, Ryan Striker, Vazquez \& Swarts, 2020) mas vão ao encontro do diagnóstico efetuado sobre como a experiência tida de ensino-aprendizagem a distância, desenvolvida nos períodos de confinamento teve, também, efeitos negativos, com destaque para o deficit de aprendizagens (Engzella, Freya \& Verhagen, 2021). No caso concreto do grupo de estudantes em estudo, fica por explorar as razões específicas que ajudam a explicar a valoração negativa feita pelos mesmos da experiência tida. Resulta do modelo de ensino desenvolvido? É influenciado pelo perfil e/ou contexto individual/familiar de aprendizagem do(a) estudante? e/ou do método pedagógico desenvolvido pelo(s) docente(s)? São dúvidas que ficam, por explorar, em investigação futura.

No que respeita aos efeitos induzidos pela situação pandémica nos processos de investigação social, a opinião partilhada pelos estudantes vai ao encontro das dúvidas que a comunidade científica, em geral, e em, particular, a das ciências sociais, tem vivenciado no último ano. Como garantir o cumprimento dos objetivos de investigação num contexto social tão modificado? O recurso a técnicas e ferramentas tecnológicas alternativas que permitam a recolha de dados a distância tem sido a opção escolhida e muito tem crescido o interesse e a produção científica sobre como tal pode ser dinamizado (Nind, Coverdade \& Meckin, 2021; Gardner, 2020).

Mas para além das dúvidas ao nível do método e das técnicas, outras questões emergem como as identificadas pelos inquiridos neste estudo, e que subjazem da dificuldade acrescida em garantir a motivação e o foco para a dúvida metódica em contexto de insegurança e cansaço como o que resulta da atual situação pandémica. 
O atual contexto é muito desafiante, se por um lado, pode ser (e já o está a ser) muito rico e propício para o desenvolvimento de investigações que capturam os seus efeitos sociais, nas mais variadas dimensões, por outro lado, coloca desafios adicionais relacionados com a capacidade emocional para gerir as dúvidas do eu, enquanto pessoa com família, com amigos e com receios e do eu-investigador com um percurso de investigação social em curso numa altura em que a distância social é obrigatória.

\section{Conclusões}

Os resultados apurados sobre os efeitos induzidos pela pandemia nos percursos de aprendizagem e de investigação social constituem uma primeira aproximação exploratória ao tema. As evidências obtidas, junto de um conjunto de estudantes, selecionado intencionalmente, a frequentar formação pós-graduada numa IES portuguesa, permitem, no entanto, que possam ser identificados alguns eixos estruturantes das experiências vivenciadas.

As categorias analíticas, que emergem da análise de conteúdo efetuada às respostas dadas pelos estudantes, tipificam a existência de um estado de espírito predominante, e transversal no tempo, de que a mudança (quer no modelo de ensino, quer no processo de investigação) criou: desconforto, alguma desmotivação, falta de foco, dificuldade acrescida na compatibilização da vida familiar com a vida académica e exigiu maiores competências no domínio das ferramentas tecnológicas que passaram a ser imprescindíveis quer para as aulas, quer para a realização do percurso de investigação.

O perfil qualitativo do estudo efetuado permitiu explorar a multidimensionalidade das apreciações feitas. As questões colocadas deram margem aos inquiridos para expressarem, com toda a liberdade, os seus sentimentos o que, combinado com a interpretação das duas questões colocadas em escala de opinião, permitiu enriquecer a significância dos resultados apurados.

No entanto, trata-se, apenas de um estudo exploratório baseado em dois momentos de recolha de dados. Para a ampliação e consolidação das primeiras evidências extraídas importará continuar a acompanhar estes estudantes de forma a verificar e analisar como a sua opinião e os seus atos evoluem ao longo do tempo. Fará sentido aplicar outras técnicas de recolha de dados como: entrevistas de grupo, fotografia reflexiva, diários pessoais reflexivos, entre outras, que permitam acompanhar a evolução das suas opiniões e sentimentos. A investigação qualitativa robustece-se no adequado e complementar recurso de técnicas de recolha e análise que ajudem a desocultar e a interpretar a significância objetiva e subjetiva das ações, das opiniões e dos sentimentos partilhados. Adicionalmente, importará explorar as adicionais questões de investigação que emergiram no domínio da forma e da eficácia do $\mathrm{EaD}$ e no da qualidade e formatos de investigação em contexto pandémico.

A atual situação introduziu e vai deixar um legado de profundos desafios societais. Entre esses desafios contam-se os que procurámos explorar preliminarmente neste estudo: de que forma o $\mathrm{EaD}$, que fomos obrigados a desenvolver como única alternativa, é eficaz? De que forma afeta positiva e/ou negativamente a aprendizagem? Como os processos de investigação social foram/são afetados pelo contexto pandémico? Como estão a reagir os estudantes em processo de investigação social ao desafio de realização das suas pesquisas num contexto societal com novos modos de relação social e individual?

Eis algumas das questões para as quais importa continuar a explorar e procurar novas e mais robustas propostas de resposta. 


\section{Referências}

Arkorful, V. \& Abaidoo, N. (2015). The role of e-learning, advantages and disadvantages of its adoption inhigher education. International Journal of Instructional Technology and Distance Learning, 12,1, 29-42. Disponível em: https://www.itdl.org/Journal/Jan_15/Jan15.pdf\#page=33

Basak, S., Wotto, M., \& Bélanger, P. (2016). A framework on the critical success factors of e-learning implementation in higher education: A review of the literature. International Journal of Educational and Pedagogical Sciences, 10, 7, 2409-2414. Disponível em: https://zenodo.org/record/1125677/files/10004989.pdf.

Barroga, E. \& Matanguihan, G.J. (2020). Fundamental Shifts in Research, Ethics and Peer Review in the Era of the COVID-19 Pandemic. JKMS, 2020 Nov 23;35(45), 1-8. https://doi.org/10.3346/jkms.2020.35.e395

Cabero Almenara, J. \& Valencia-Ortiz, R. (2020). Y el COVID-19 Transformó al Sistema Educativo: reflexiones y experiencias por aprender. Internacional Journal of Educational Research and Innovation, v. 15, 217-227. Disponível em: https://hdl.handle.net/11441/101185

Engzella, P., Freya, A., \& Verhagen, M.K. (2021). Learning loss due to school closures during the COVID-19 pandemic. PNAS 2021, Vol. 118, No. 17, https://doi.org/10.1073/pnas.2022376118

Gardner, B. (2020, June 17). Challenges of Doing Research in a Pandemic: Reframing, Adapting and Introducing qualitative methods. Blog post. Disponível em: https://ijsrm.org/2020/06/17/challenges-of-doing-research-in-a-pandemic-reframing-adaptingand-introducing-qualitative-methods/

Hodges, C., Moore, S., Lockee, B., Trust, T., \& Bond, A. (2020). The difference between emergency remote teaching and online learning. Educause Review. Disponível em: https://bit.ly/3b0Nzx7

Kara, H., \& Khoo, S. (Eds.). (2020). Researching in the Age of COVID-19 Vol 2: Volume II: Care and Resilience. Bristol: Bristol University Press. doi:10.2307/j.ctv18dvt4f

Katz V.S, Jordan A.B, \& Ognyanova, K. (2021) Digital inequality, faculty communication, and remote learning experiences during the COVID-19 pandemic: A survey of U.S. undergraduates. PLoS ONE. 16(2): e0246641. https://doi.org/10.1371/journal.pone.0246641

Mineiro, A. \& Lagarto, J.L. (2020). Guia de boas práticas de ensino online em contexto de emergência para alunos surdos durante a pandemia da doença COVID-19. Guidelines 2020 para o Ministério da Educação/ Direção-Geral da Educação. Universidade Católica Portuguesa. Disponível em: https://www.dge.mec.pt/sites/default/files/guia_de_boas_praticas_de_ensino_online_em_con texto_de_emergencia_para_alunos_surdos_durante_a_pandemia_da_doenca_covid_19.pdf.

Moore, J., Dickson-Deane, C. \& Galyen, K. (2011). E-Learning, online learning, and distance learning environments: Are they the same?. The Internet and Higher Education. 14(2), 129135. https://doi.org/10.1016/j.iheduc.2010.10.001

Nind, M., Coverdale, A. \& Meckin, R. (2021). Changing Social Research Practices in the Context of Covid-19: Rapid Evidence Review. University of Southampton: National Centre for Research Methods (NCRM) Social Sciences. Disponível em: https://www.ncrm.ac.uk/research/socscicovid19/

Pearson, M., Singelmann, M., Ryan Striker, P., Vazquez, M. \& Swartz, E. (2020). Benefits of LongDistance Collaboration in Higher Education Institutions to Train Students in Innovation Practices. Paper presented in the 2020 American Society for Engineering Education Virtual Conference. Disponível em: http://www.asee.org/public/conferences/172/papers/30827/view

Saldana, J. (2009). The Coding Manual for Qualitative Researchers. London: Sage. 